\title{
Postoperative opioids and risk of respiratory depression - A cross-sectional evaluation of routines for administration and monitoring in a tertiary hospital
}

https://doi.org/10.1515/sjpain-2020-0060

Received April 20, 2020; accepted September 17, 2020; published online October 28, 2020

\begin{abstract}
Objectives: Opioids are the most potent analgesics in the treatment of postoperative pain. Respiratory depression is, however, a serious side effect. The aims of this study were to evaluate current practice and routines for post-operative administration of opioids in a Norwegian university hospital and to evaluate whether the clinical safeguards adequately protected patients' safety regarding risk of respiratory depression.

Methods: The study had a retrospective cross-sectional design and included 200 patients, treated with opioids postoperatively. The patients were treated in a postanesthesia care unit (PACU) before transferal to a surgical ward. Relevant data such as opioid dosages, routes of administration, sedation and respiratory function, routines for patient monitoring, and numbers of patients with opioid induced respiratory depression was collected.

Results: Two patients (1\%) developed respiratory depression that needed naloxone to reverse the effect, and 32 patients $(16 \%)$ had a respiratory rate $(\mathrm{RR})<10 / \mathrm{min}$, which may have been caused by opioids. In the PACU, the patient's RR was evaluated on a routine base, but after transferal to a surgical ward RR documented in only $7 \%$ of the patients.
\end{abstract}

\footnotetext{
*Corresponding author: Karoline Kolås Andersen, Department of Anesthesiology, Haraldsplass Deaconess Hospital, Bergen, Norway, E-mail: karoline.kolas@gmail.com

Gunnvald Kvarstein, Department of Clinical Medicine, UIT, The Arctic University of Norway, Troms $\varnothing$, Norway; and Department of Anesthesiology, University Hospital of North Norway (UNN), Tromsø, Norway, E-mail: gunnvald.kvarstein@uit.no
}

Conclusions: The lack of routines for patient monitoring, especially RR, represented a risk of not detecting opioid induced respiratory depression.

Keywords: clinical monitoring; opioids; pain treatment; post-operative; respiratory depression; tertiary hospital setting.

\section{Introduction}

Opioids are the most potent analgesics in the treatment of postoperative pain. Respiratory depression is, however, a serious side effect. Since 2001, at least nine patients have died due to opioid overdose administered by health care providers in Norway, and in three cases, this happened post-operatively ${ }^{1}$. In a large systematic review of 165 articles, addressing effects of opioids in a postoperative setting [1], the authors calculated an incidence of $0.3 \%$ for opioid induced and naloxone requiring respiratory depression. Respiratory rates (RR) below 10/min were observed in 1.1\% of the cases. Another study found the risk of respiratory depression postoperatively to be highest during the first $24 \mathrm{~h}$, including $77 \%$ of the incidents [2]. Others have claimed that respiratory depression can be avoided by individualized pain treatment and systematic monitoring focusing on sedation and respiratory depression [3].

The aims of our study were to evaluate current practice and routines for post-operative administration of opioids in a Norwegian university hospital and evaluate whether the clinical safeguards adequately protected patients' safety regarding risk of respiratory depression. An overriding routine or guideline for pain intensity scoring and monitoring of patients who received opioids postoperatively in

1 Fatalities reported by the media. 
the University Hospital of North Norway (UNN) in Tromsø had not been implemented. Therefore, we hypothesized that patients were not sufficiently monitored to discover respiratory depression. The original study was presented in a master thesis in 2017 and is published in a full version in Norwegian and accessible online [4].

\section{Methods}

The study had a retrospective cross-sectional design including 200 patients, treated with opioids postoperatively in 2015 at UNN Tromsø. The patients were taken care of in a post-anesthesia care unit (PACU) and then transferred to one of three surgical wards. All surgical patients (orthopedic, abdominal, endocrine or urology), were $\geq 18$ years old and had received at least one dose of a potent opioid postoperatively.

All data was collected from the electronic patient journal from arrival to the PACU until $22 \mathrm{pm}$ the following post-operative day. Data describes opioid dosages, routes of administration, sedation, respiratory function, RR and routines for patient monitoring. Opioid dosages were converted to Morphine Milligram Equivalents (MME, i.e., mgs morphine given orally). Epidural dosages could not be converted and were calculated and presented separately (see Table 1). We counted the numbers of patients with naloxone requiring respiratory depression, patients with a $\mathrm{RR}<10 / \mathrm{min}$, and how many of these who had a $\mathrm{RR}<8 / \mathrm{min}$, patients with oxygen saturation $\left(\mathrm{SpO}_{2}\right)<90 \%$, and patients with arterial hypoxemia and hypercapnia by cut off values of $\mathrm{PaO}_{2}<8 \mathrm{kPa}$ and $\mathrm{PaCO}_{2}>6 \mathrm{kPa}$ or end tidal $\mathrm{CO}_{2}>6 \mathrm{kPa}$, respectively. Descriptive statististics were used.

\section{Results}

Thirty-two (16\%) patients had a $\mathrm{RR}<10 / \mathrm{min}$, and among these $12(6 \%)$ had a $R R<8 / \mathrm{min}$, while $24(12 \%)$ had $\mathrm{SpO}_{2}<90 \%$ and 10 (5\%) had hypoxia and/or hypercapnia on arterial blood gas test (ABG). Two patients (1\%), one in the PACU and another after arrival in the surgical ward, developed respiratory depression and needed naloxone to reverse the effect (see Table 2).

Average MME during the first $24 \mathrm{~h}$ was $55.5 \mathrm{mg}$ and more than $10 \%$ of the patients received more than $100 \mathrm{mg}$. Among patients who received fentanyl epidurally, the average daily dose was $332 \mu \mathrm{g}$ (see Table 3).

In the PACU opioids were mostly given intravenously (85\%) and/or epidurally (26\%). Relatively few patients (7\%) received opioids orally. Transdermal and intramuscular administration was infrequent (3\% and $0.5 \%$, respectively), and none were given opioids subcutaneously or rectally. In the surgical wards, the proportion who received opioids intravenously (37\%), equaled the number
Table 1: Conversion factors to orally administered morphine milligram equivalents (MME) for the different opioids and routes of administration.

\begin{tabular}{llr}
\hline Drug & Route of administration & Ratio \\
\hline Morphine & Oral & 1 \\
Oxycodone & IV/SC/IM & 3 \\
& Oral & 1.65 \\
Buprenorphine & IV/SC/IM & 6 \\
& Dermal & 100 \\
Fentanyl & Sublingual & 46.5 \\
& Dermal & 109 \\
& Epidural & $\mathrm{N} . \mathrm{A}$ \\
& IV/SC/IM & 5000 \\
Hydromorphone & Sublingual/nasal & 50 \\
Ketobemidone & Oral & 5.8 \\
& Oral & 1 \\
Pethidine & IV/SC/IM & 3 \\
& Rectal & 0.08 \\
Codeine & IV/SC/IM & 0.3 \\
Tramadol & Oral & 0.1 \\
Tapentadol & Oral & 0.15 \\
\hline Conersion & Oral & 0.25 \\
\hline
\end{tabular}

Conversion factors are provided by the Norwegian handbook for medical drugs "Norsk legemiddelhåndbok", Chapter L20.2 and by "Guideline for opioid conversion" from the University Hospital of North Norway and "Opioid Dose Equivalence" from Faculty of Pain Medicine ANZCA. NA, not applicable. We could not find a valid conversion factor from epidural to oral fentanyl administration.

Table 2: Number of patients with respiratory depression or impaired respiratory function postoperatively ( $N$ : 200).

\begin{tabular}{lrrr}
\hline Impaired respiratory function & $\begin{array}{r}\text { PACU } \\
\mathbf{n}, \%\end{array}$ & $\begin{array}{r}\text { Surgical ward } \\
\mathbf{n ,} \%\end{array}$ & $\begin{array}{r}\text { Total } \\
\mathbf{N}, \%\end{array}$ \\
\hline $\begin{array}{l}\text { Respiratory depression with } \\
\text { naloxone requirement }\end{array}$ & $1(0.5)$ & $1(0.5)$ & $2(1)$ \\
$\mathrm{RR}<10 / \mathrm{min}$ & $31(15.5)$ & $2(1)$ & $32(16)$ \\
$\mathrm{RR}<8 / \mathrm{min}$ & $12(6)$ & $1(0.5)$ & $12(6)$ \\
$\mathrm{SpO}_{2}<90 \%$ & $6(3)$ & $18(9)$ & $24(12)$ \\
Hypoxia or hypercapnia (ABG) & $10(5)$ & $0(0)$ & $10(5)$ \\
\hline
\end{tabular}

PACU, post-anesthesia recovery unit; $\mathrm{RR}$, respiratory rate; $\mathrm{SpO}_{2}$, oxygen saturation measured by pulse-oximetry; $A B G$, arterial blood gas test.

treated by oral administration (36.5\%). In cases where epidural or transdermal administration was established, the treatment was continued in the ward. Only one patient was given opioids intramuscularly or rectally, and none subcutaneously. Both in the PACU and in the surgical wards most patients received opioids by one single route, and only a few patients through three or four routes. We noted that the physicians' discretion rarely defined maximal dose of supplemental opioids. 
Table 3: Total opioid dosages and routes of administration ( $N: 200)$.

\begin{tabular}{|c|c|c|}
\hline \multirow{2}{*}{$\begin{array}{l}\text { Total opioid dosages } \\
\text { Numbers and percentages of patients } \\
\text { given }>100 \mathrm{MME}^{\star} \text { within } 24 \mathrm{~h} \\
\text { Average } \mathrm{MME} \text { given within } 24 \mathrm{~h} \text { (min-max) } \\
\text { Average dose epidural fentanyl within } 24 \mathrm{~h} \\
\text { among } 51 \text { patients } \mu \mathrm{g} \text { (min-max) }\end{array}$} & \multicolumn{2}{|r|}{$\frac{n, \%}{21(10.5)}$} \\
\hline & \multicolumn{2}{|c|}{$\begin{array}{l}55.5\left(0^{\star *}-308.6\right) \\
332 \mu \mathrm{g}(96-576)\end{array}$} \\
\hline Routes of administration & $\begin{array}{r}\text { PACU } \\
\text { n, \% }\end{array}$ & $\begin{array}{r}\text { Surgical } \\
\text { ward } \\
\mathbf{n}, \%\end{array}$ \\
\hline IV & $\begin{array}{r}169 \\
(84.5)\end{array}$ & $74(37.0)$ \\
\hline Oral & $13(6.5)$ & $73(36.5)$ \\
\hline Epidural & $51(25.5)$ & $51(25.5)$ \\
\hline Dermal & $6(3.0)$ & $6(3.0)$ \\
\hline IM & $1(0.5)$ & $1(0.5)$ \\
\hline Rectal & $0(0.0)$ & $1(0.5)$ \\
\hline SC & $0(0.0)$ & $0(0.0)$ \\
\hline Number of routes applied simultaneously & $\mathrm{n}, \%$ & $\mathrm{n}, \%$ \\
\hline $0^{\star \star \star}$ & $9(4.5)$ & $64(32)$ \\
\hline 1 & $\begin{array}{r}145 \\
(72.5)\end{array}$ & $77(38.5)$ \\
\hline 2 & $43(21.5)$ & $51(25.5)$ \\
\hline 3 & $3(1.5)$ & $7(3.5)$ \\
\hline 4 & $0(0.0)$ & $1(0.5)$ \\
\hline
\end{tabular}

*MME, morphine milligram equivalents (1 MME equals $1 \mathrm{mg}$ morphine by oral administration); **Three patients received only epidural analgesia. Since there is no valid conversion factor from epidural to oral fentanyl administration, the epidural dose of fentanyl was not included in MME and presented separately. Epidural dose of fentanyl were imputed as zero mgs in the MME calculation; ***Patients who received opioids either only in the PACU or after arrival to the surgical ward; IV, intravenous. IM, intramuscular, SC, subcutaneous. PACU, Post-anesthesia care unit.

When monitoring the patient, sedation level was usually documented as a qualitative description rather than a quantitative score. Around $10 \%$ of the journals provided no sedation level. After a supplementary opioid dose, sedation level was documented in $9 \%$ of all dosages given in the PACU and only $3 \%$ in the surgical wards (see Table 4).

In the PACU, RR and $\mathrm{SpO}_{2}$ were documented at least once and respiratory function was assessed by either a qualitative description, capnography and/or blood gas levels in $1 / 3$ of the patients. RR was documented after $77 \%$ of the supplementary opioid doses. During the stay in the surgical ward, however, RR was rarely documented (7\%) and other tools than oxygen saturation was seldom used to assess respiratory function.
Table 4: Methods and frequency for patient monitoring (N: 200).

\begin{tabular}{lrr}
\hline Vital sign assessment & PACU & $\begin{array}{r}\text { Surgical } \\
\text { ward } \\
\mathbf{n , ~ \%}\end{array}$ \\
\hline Sedation assessment & $\mathbf{n , ~ \%}$ & \\
Qualitative description & & \\
Qualitative description + GCS & $282(91)$ & $177(88.5)$ \\
None & $18(9)$ & $0(0)$ \\
Average number of documented & $0.3(0.0-1.5)$ & $0.1(0.2-3.7)$ \\
sedation & & \\
level per hour (min-max) & & \\
Ratio number documented sedation & $45 / 531(8.5)$ & $7 / 272(2.6)$ \\
level and supplemental opioid & & \\
dosages & & \\
Respiratory assessment & & \\
RR & $200(100)$ & $14(7)$ \\
Pulse oximetry & $200(100)$ & $124(62)$ \\
Capnography & $1(0.5)$ & $0(0)$ \\
Arterial blood gas test & $47(23.5)$ & $1(0.5)$ \\
Qualitative description & $24(12)$ & $36(18)$ \\
Average number of documented RR per & $1.0(0.0-0.5)$ & $0.0(0.0-0.4)$ \\
hour (min - max) & & \\
Ratio number documented RR and & $410 / 531$ & $7 / 272(2.6)$ \\
supplemental opioid dosages & $(77.2)$ & \\
\hline
\end{tabular}

GCS, Glasgow Coma scale; RR, respiratory rate; PACU, Postanesthesia care unit.

\section{Discussion}

In this study $1 \%$ of the 200 patients developed respiratory depression requiring naloxone, and $16 \%$ a documented $\mathrm{RR}<10 / \mathrm{min}$, which may indicate that ventilation was affected by opioids. This represents a substantially higher rate compared to the incidence of naloxone requirement at $0.3 \%$ and $\mathrm{RR}<10 / \mathrm{min}$ or $8 / \mathrm{min}$ at $1.1 \%$ presented in a large systematic review by Cashman et al. (1) including pooled data from 165 studies and nearly 20000 patients. The higher incidences in our study may reflect a small sample size, and probably methodical differences in the ways of data collection. Due to the lack of documented RR in the surgical wards, however, we cannot rule out other cases with respiratory depression or serious respiratory impairment, which went undiscovered. Unfortunately, the present study design cannot derive causal relationships between opioid consumption and respiratory depression or impaired respiratory function, which could have been affected by for example sleep apnea, chronic obstructive pulmonary disease, residual muscular relaxation, type of surgery et cetera. However, the two cases of naloxone administration was thoroughly documented and left no uncertainty regarding opioid overdose as the cause of respiratory depression. 
The large variation in opioid consumption in our sample does not surprise considering the variation in surgical procedures and an inter-individual variation in pain intensity which has been shown even after similar surgical procedures $[5,6]$. In our material, average opioid consumption after $24 \mathrm{~h}$ equaled $55.5 \mathrm{mg}$ morphine and more than $10 \%$ of the patients received more than $100 \mathrm{mg}$ during a time period of $24 \mathrm{~h}$. For one patient the total opioid dose equaled $309 \mathrm{mg}$ morphine. A dose of 40-60 mg morphine can be toxic in an opioid naive patient $[7,8]$, and still, the physicians did not routinely set a maximal dose of supplemental opioid. Although the dosages were spread over several hours, we question whether this practice was adequate regarding the risk of opioid overdose. With a preset maximum opioid dose the physician on duty would have been contacted whenever the patient demanded higher opioid dosages, and been able to exclude possible postoperative complications, evaluate the opioid regime and discuss other treatment measures.

A total of 51 patients received fentanyl epidurally additional to other opioids or as the only route. Unfortunately, we could not find a valid conversion factor from epidural to oral opioids, and therefore the fentanyl dosages were not included in the number of MME. Considering the high number of patients receiving epidural analgesia, the total opioid dose in our material, presented as MME, is systematically underestimated. Some of the patients received different opioids by three or four different routes. Different routes of administration increase risk of respiratory depression [9]. In such cases, the time point of maximal blood concentration and effect is hard to foresee and may from a pharmacodynamic and pharmacokinetic perspective expose the patient to an unnecessary high risk of undetected overdose if the patient is not sufficiently monitored.

Sedation usually occurs at lower opioid dosages and is a sensitive indicator for a forthcoming respiratory depression [10]. Some authors recommend an evaluation of sedation and RR every hour during the first $24 \mathrm{~h}$ postoperatively [10], and more often in cases with a high risk of side effects [11]. Among patients who receive small dosages, such a frequent surveillance may seem exaggerated. We found no systematic documentation on sedation level in the records in this study. This indicates that sedation was not systematically assessed after supplemental opioid doses, which is essential to detect an overdose. In the PACU, the routine for evaluating RR was sufficient in relation to international standard. In the surgical wards however, RR was documented in only $7 \%$ of the patients. The risk of overseeing serious respiratory depression was therefore present.
At the time of data collection, there was no overriding, institutional guideline for clinical monitoring after postoperative opioid administration implemented. The clinical monitoring should include a systematic evaluation of pain intensity, as well as sedation and respiratory rate to reduce the risk of overdose and respiratory depression. Our findings indicate a strong need for such routines. Though limited by a small sample size, our findings may be generalized to other hospitals without such guidelines.

\section{Conclusion}

The monitoring of patients receiving opioids in the surgical wards seemed not sufficient with a risk of not detecting opioid induced respiratory depression. There were no overriding routine or guidelines available for pain intensity scoring and monitoring of patients who receive opioids postoperatively. Implementation of such guidelines would improve the postoperative pain treatment and increase patient safety.

Research funding: The authors state no funding involved. Author contributions: All authors have accepted responsibility for the entire content of this manuscript and approved its submission.

Competing interests: The authors state no conflict of interest.

Informed consent: As a quality assurance project it did not require informal consent from the indivuals included.

Ethical approval: Approval to conduct the study was given by the institutional data protection officer at The University Hospital of North Norway. As a quality assurance project the project did not require any approval by The Regional Ethical Committee.

\section{References}

1. Cashman JN, Dolin SJ. Respiratory and haemodynamic effects of acute postoperative pain management: evidence from published data. Br J Anaesth 2004;93:212-23.

2. Taylor SJ, Kirton OC, Staff II, Kozol RA. Postoperative day one: a high risk period for respiratory events. Am J Surg 2005;190: 752-6.

3. Smith LH. Opioid safety: is your patient at risk for respiratory depression? Clin J Oncol Nurs 2007;11:293.

4. Andersen KK, Johansen A, Kvarstein G. En kartlegging av rutiner og praksis for postoperativ administrasjon av opioider ved et norsk universitetssykehus - med fokus på pasientsikkerhet: UiT. Norway: The Arctic University of Norway; 2017. 
5. Palada V, Kaunisto M, Kalso E. Genetics and genomics in postoperative pain and analgesia. Curr Opin Anaesthesiol 2018; 31:1.

6. Bisgaard T, Klarskov B, Rosenberg J, Kehlet H. Characteristics and prediction of early pain after LC. Pain 2001;90:261-9.

7. Norwegian Poison Information Center, Norwegian Institute of Public Health. Treatment after morphine overdose. Helsebiblioteket. Available from: http://www.helsebiblioteket. no/224305.cms [Accessed 2 Feb 2017].

8. Norwegian handbook for medical drugs. G12.5.13M Drug Overdose And Treatment. Available from: https://www.
legemiddelhandboka.no/G12.5.13/Forgiftninger [Accessed 4 Jul 2020].

9. Gupta KPA, Nagappa M, Wong J, Abrahamyan L, Chung F. Risk factors for opioid-induced respiratory depression and failure to rescue: a review. Curr Opin Anaesthesiol 2018;31:110-9.

10. Pasero CC. Assessment of sedation during opioid administration for pain management. J PeriAnesthesia Nurs 2009;24:186-90.

11. Pasero CC. Opioid-induced sedation and respiratory depression: evidence-based monitoring guidelines. J PeriAnesthesia Nurs 2012;27:208-11. 